\title{
Investigation of clinical hypocalcaemia in cattle and goats at the selected veterinary hospitals in Bangladesh and India
}

\begin{abstract}
Hypocalcaemia is a metabolic disease of cattle, goat, sheep, buffalo and birdet hypocalcaemia occurs when the level of Calcium in blood goes to down $10 \mathrm{mg} /$ $\mathrm{dl}$ or less. The study was conducted to estimate the proportionate prevalence of hypocalcaemia in cattle and goat and its animal level distribution at Upazila Veterinary Hospital, Chakaria; Shahedul Alam Quaderi Teaching Veterinary Hospital, Chittagong and Madras Veterinary College, India. The study also aimed to describe clinical signs of hypocalcaemia and treatment given for it. Data obtained were analyzed by STATA-11. Hypocalcemic cases were significantly higher in cattle than in goat within study site comparison (UVH: $14 \%$ versus $8.3 \%, p \leq 0.05$, SAQTVH: $20 \%$ vs $17.4 \%$ $p \leq 0.05$ and MVC: $20 \%$ vs $10 \%, p \leq 0.05)$. Both cross breed cattle and Jamnaparihad more hypocalcemic cases (13 and 11 , respectively) than that of local indigenous cattle and goat ( 5 and 4 , respectively). Female cattle and goat had higher cases (11 and 13 , respectively) than male ( 7 and 2 , respectively). The predominant clinical sign was unable to move for cattle and recumbency for goat. Eleven of 18 hypocalcemic cattle were recovered, whereas 12 of 15 hypocalcemic goats were recovered after the treatment.
\end{abstract}

Keywords: hypocalcaemia, proportionate prevalence, cattle, goat
Volume 5 Issue I - 2017

\author{
Md Nurul Quader,' Kazi Muhammad Fakhrul \\ Islam,' Shah Jalal, ${ }^{2}$ Saroj Kumar, ${ }^{4}$ Md Iqbal \\ Hossain, ${ }^{3}$ Ashifimtiaj Shawn, ' Mdahasanul \\ Hoque $^{4}$ \\ 'Department of Physiology Biochemistry and Pharmacology, \\ Chittagong Veterinary and Animal Sciences University, India \\ ${ }^{2}$ Department of Microbiology and Veterinary Public Health, \\ Chittagong Veterinary and Animal Sciences University, India \\ ${ }^{3}$ Department of Genetics and Animal Breeding, Chittagong \\ Veterinary and Animal Sciences University, India \\ ${ }^{4}$ Department of Medicine and Surgery, Chittagong Veterinary \\ and Animal Sciences University, India
}

\begin{abstract}
Correspondence: Md Nurul Quader, Department of Physiology Biochemistry and Pharmacology, Chittagong Veterinary and Animal Sciences University, Room no: 8I4, MA Hannan Hall, Chittagong, Bangladesh, Tel +88 01675440517 , Email nquaderdvmI5@gmail.com
\end{abstract}

Received: March 05, 2015 | Published: February 24, 2017

\section{Introduction}

Hypocalcaemia is a nutritional deficiency of Calcium $(\mathrm{Ca})$ in blood. It occurs in different livestock species such as cattle, goat etc when the blood $\mathrm{Ca}$ level goes down to $10 \mathrm{mg} / \mathrm{dl}$ or less. It is characterized by anorexia, lethargic, unable to move, recumbency, subnormal rectal temperature and sluggish pupillary light reflection and relaxed of anal sphincter. ${ }^{1}$ The potential causes of hypocalcaemia are low dietary $\mathrm{Ca}$ and vitamin $\mathrm{D}$ supplement, improper ratio of $\mathrm{Ca}$ and Phosphorus (P) (2:1) and also imbalance of parathyroid hormone and calcitonin. ${ }^{2,3}$ Alkalosis due to excessive cations of Potassium, Sodium, $\mathrm{Ca}$ and Magnesium predisposes the animal to milk fever and subclinical hypocalcaemia. ${ }^{4}$ Hypomagnesaemia in periparturient cow also increases the susceptibility of hypocalcaemia and milk fever. ${ }^{5}$

The prevalence of hypocalcaemia was reported to be $15 \%$ in cattle, $9 \%$ in goat, $7 \%$ in sheep and $12 \%$ in buffalo in Bangladesh ${ }^{6}$ whereas $10 \%$ in cattle, $9 \%$ in goat, $8 \%$ in sheep and $14 \%$ in buffalo in India. ${ }^{7}$ The identified potential risk factors associated with hypocalcaemia includes species, age, sex, breed and stage of production period. Cattle were reported to be more susceptible than any other livestock species. ${ }^{2}$ Cross breed, female, older animals and lactating animals were commonly affected by hypocalcaemia. ${ }^{3}$

Hypocalcaemia greatly reduces the milk production, rumenand abomasal motility and increases the risk of abomasal displacement. ${ }^{8}$ It also reduces feed intake so that greater body fat mobilization occurs in early lactation. ${ }^{7}$ Hypocalcaemia also directly impairs with immune cell responding to an activating stimulus. ${ }^{9}$

The available treatment options were as follows ${ }^{10,11}$ Treatment of hypocalcemia should be given as early as possible, especially if recumbency occurs. The fastest way to restore normal plasma $\mathrm{Ca}$ concentration is to administer an intravenous injection of Ca salts.

a. The most effective IV Ca dose is about $2 \mathrm{~g} \mathrm{Ca} / 100 \mathrm{~kg}$ body weight (BW) but it is safe to administer the Ca at a rate of $1 \mathrm{~g} / \mathrm{min}$. If administered too rapidly, fatal arrhythmia of the heart and cessation during systole can occur. Intravenous $\mathrm{Ca}$ treatment elevates blood $\mathrm{Ca}$ above normal for about 4 hours.

b. Calcium salts can also be injected subcutaneously (SC). The amount of $\mathrm{Ca}$ that can be injected into a single $\mathrm{SC}$ site should be limited to $1-1.5 \mathrm{gCa} / 100 \mathrm{~kg} \mathrm{BW}$.

c. Calcium preparations designed for intramuscular administration are Calevulinate and $\mathrm{Ca}$ lactate. The dose is $0.5-1.0 \mathrm{gCa} / 100 \mathrm{~kg} \mathrm{BW}$ and injected at 6-10 injections site.

The hypocalcaemia can be controlled by followings ways: ${ }^{8,10,11}$

i. Oral $\mathrm{Ca}$ treatment at calving to prevent hypocalcemia to the fresh cow. Best results are obtained with doses of $\mathrm{Ca}$ between 50 and $125 \mathrm{gCa} /$ dose. For the best control of hypocalcemia a dose is given at calving and again 24 hours after calving.

ii. The benefit of adding oral $\mathrm{Ca}$ on top of a properly or mulated low dietary cation diet programmed does not seem to warrant the added expense.

iii. Maintain proper proportion of $\mathrm{Ca}$ in feed.

The present clinical study was conducted at a Government Veterinary Hospital and Teaching Veterinary Hospitals in Bangladesh 
and India. Among different cases of nutritional deficiency hypocalcemic cases were predominantly found and therefore clinical hypocalcaemia in cattle and goat were considered to investigate the details. The study was aimed to estimate the proportionate prevalence of hypocalcaemia in cattle and goat with its animal level distribution. The study also described clinical signs of the hypocalcaemia and treatment given against the cases.

\section{Materials and methods}

The present study was conducted at a Government Veterinary Hospital and Teaching Veterinary Hospital in Bangladesh and India. The Veterinary Hospitals included Upazila Veterinary Hospital, Chakaria, Chittagong, Bangladesh (13 January to 15 March 2015), Shahedul Alam Quaderi Teaching Veterinary Hospital, Chittagong Veterinary and Animal Sciences University, Bangladesh (23 to 28 April 2015) and Madras Veterinary College, Chennai, India (13 June to 9 July 2015, but this study based on 2days worked at Large Animal Section).Both retrospective and prospective hypocalcemic cases were included in this study. Species, breed, age, sex, clinical signs (according to clinical and physical examination) and drug details for each individual case were recorded using the record keeping sheet.

In order to calculate the proportionate prevalence of hypocalcaemia in cattle and goats cases other than hypocalcemic cases were also recorded. The clinical hypocalcaemia was diagnosed based on clinical sings like unable to move, recumbency, subnormal rectal temperature and sluggish pupillary light reflection, and blood $\mathrm{Ca}$ level (below
$10 \mathrm{mg} / \mathrm{dl}$ or less) (for some cases) and also response to Ca therapy(for some cases).

Data obtained were entered into Microsoft excel 2007 and exported to STATA-11(Stata crop, 4905, Lake Way Drive, College Station, Texas 778-45, USA) for statistical analysis. Descriptive statistics were performed. Fisher's exact test was applied to assess the difference of proportion of hypocalcemic and non hypocalcemic cases for different factors. The results were expressed as frequency and percentage against categories of each variable under the study. The level of significance was set at $\leq 0.05$.

\section{Results}

\section{Proportionate prevalence and distribution of clinical hypocalcaemia in cattle and goat}

Hypocalcemic cases were significantly higher in cattle than in goat within study site comparison (UVH: $14 \%$ versus $8.3 \%, p \leq 0.05$; SAQTVH: $20 \%$ vs $17.4 \%, p \leq 0.05$ and MVC: $20 \%$ vs $10 \%, p \leq 0.05$ ) (Table 1). Cross breed, female and younger cattle were frequently affected by hypocalcaemia across study sites in this study (Table 2). Jamnapari and female goats had more cases (11 and 13, respectively) in comparison with the local and male goats (4 and 2, respectively). Older goats were commonly affected by hypocalcaemia (Table 3 ). Jamnapari and female goats had more cases (11 and 13, respectively) in comparison with the local and male goats (4 and 2, respectively). Older goats were commonly affected by hypocalcaemia (Table 3 ).

Table I Proportionate prevalence of clinical hypocalcaemia in cattle and goat at the selected Veterinary Hospitals in Bangladesh and India

\begin{tabular}{|c|c|c|c|c|c|c|c|c|c|c|c|c|}
\hline \multirow{3}{*}{ Species } & \multicolumn{4}{|c|}{ UVH } & \multicolumn{4}{|c|}{ SAQTVH } & \multicolumn{4}{|c|}{ MVC } \\
\hline & \multicolumn{4}{|c|}{ Hypocalcaemia } & \multicolumn{4}{|c|}{ Hypocalcaemia } & \multicolumn{4}{|c|}{ Hypocalcaemia } \\
\hline & $\mathbf{N}$ & $+(\%)$ & - & $p$ & $\mathbf{N}$ & $+(\%)$ & - & $p$ & $\mathbf{N}$ & $+(\%)$ & - & $p$ \\
\hline Cattle & 100 & $14(14 \%)$ & 86 & & 5 & I (20\%) & 4 & & 15 & $3(20 \%)$ & 12 & \\
\hline & & & & 0.73 & & & & 0.63 & & & & 0.49 \\
\hline Goat & 120 & $10(8.3 \%)$ & 110 & & 23 & $4(17.4 \%)$ & 19 & & 10 & I (I0\%) & 9 & \\
\hline
\end{tabular}

UVH, upazila veterinary hospital; SAQTVH, shahedul alam quaderi teaching veterinary Hospital; MVC, madras veterinary college

Table 2 Frequency distribution of proportionate prevalence of clinical hypocalcaemia in cattle at the selected Veterinary Hospitals in Bangladesh and India

\begin{tabular}{|c|c|c|c|c|}
\hline \multirow{2}{*}{ Variable } & \multirow{2}{*}{ Category } & \multirow{2}{*}{$\begin{array}{l}\text { UVH } \\
\mathbf{N}\end{array}$} & \multirow{2}{*}{$\begin{array}{l}\text { SAQTVH } \\
\mathbf{N}\end{array}$} & \multirow{2}{*}{$\begin{array}{l}\text { MVC } \\
\mathbf{N}\end{array}$} \\
\hline & & & & \\
\hline \multirow{3}{*}{ Breed } & Local & 4 & 0 & I \\
\hline & & & & \\
\hline & Cross breed & 10 & I & 2 \\
\hline \multirow{3}{*}{ Sex } & Male & 6 & I & 0 \\
\hline & & & & \\
\hline & Female & 8 & 0 & 3 \\
\hline \multirow{3}{*}{ Age(month) } & $<6$ & 8 & I & 0 \\
\hline & & & & \\
\hline & $>6$ & 6 & 0 & 3 \\
\hline
\end{tabular}

$\mathrm{N}$, frequency number; UVH, upazila veterinary hospital; SAQTVH, shahedul alam quaderi teaching veterinary hospital; MVC, madras veterinary college
Table 3 Frequency distribution of proportionate prevalence of clinical hypocalcaemia in goat at selected veterinary hospitals in Bangladesh and India

\begin{tabular}{|c|c|c|c|c|}
\hline \multirow{2}{*}{ Variable } & \multirow{2}{*}{ Category } & \multirow{2}{*}{$\begin{array}{l}\text { UVH } \\
\mathbf{N}\end{array}$} & \multirow{2}{*}{$\begin{array}{l}\text { SAQTVH } \\
\mathbf{N}\end{array}$} & \multirow{2}{*}{$\begin{array}{l}\text { MVC } \\
\mathbf{N}\end{array}$} \\
\hline & & & & \\
\hline & Local & 2 & I & I \\
\hline \multicolumn{5}{|l|}{ Breed } \\
\hline & Jamnapari & 7 & 4 & 0 \\
\hline & Male & 0 & 2 & 0 \\
\hline \multicolumn{5}{|l|}{ Sex } \\
\hline & Female & 10 & 2 & I \\
\hline & $<6$ & 3 & 3 & 0 \\
\hline \multicolumn{5}{|c|}{ Age(month) } \\
\hline & $>6$ & 7 & 2 & I \\
\hline
\end{tabular}

$\mathrm{N}$, frequency number; UVH, upazila veterinary hospital; SAQTVH, shahedul alam quaderi teaching veterinary hospital; MVC, madras veterinary college 


\section{Distribution of clinical signs of hypocalcaemia in cattle} and goat

Predominant clinical sign in cattle was unable to move (12) followed by recumbency (9) and sluggish pupilary light reflection (7). More frequently observable sign in goat was recumbency (8) followed by sluggish pupillary light reflection (7) and unable to move (6) (Table 4). Calcium level was determined only for 6hypocalcemic case in MVC $(5-7 \mathrm{mg} / \mathrm{dl})$ and 2 cases in SAQTVH $(7.9 \mathrm{mg} / \mathrm{dl})$ and 6hypocalcemic goats in SAQTVH (6.3-7mg/dl) (Figure 1).

\section{Treatment given against hypocalcaemia}

The recovery rate after treatment was 7 of 11 for hypocalcemic cattle and 8 of 10 for hypocalcemic goats (Table 5).
Table 4 Distribution of clinical signs recorded for hypocalcaemia in cattle $(\mathrm{N}=18)$ and goat $(\mathrm{N}=15)$

\begin{tabular}{lll}
\hline \multirow{2}{*}{ Clinical Signs } & Cattle & Goat \\
\cline { 2 - 3 } & $\mathbf{N}$ & $\mathbf{N}$ \\
\hline Recumbency & 9 & 8 \\
Sluggish Pupillary Light Reflection & 7 & 7 \\
Unable to Move & 12 & 6 \\
\hline
\end{tabular}

$\mathrm{N}$, Frequency number

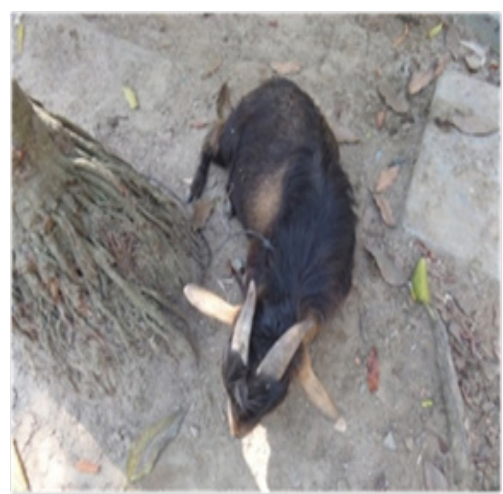

Figure IA Sternal recumbency.

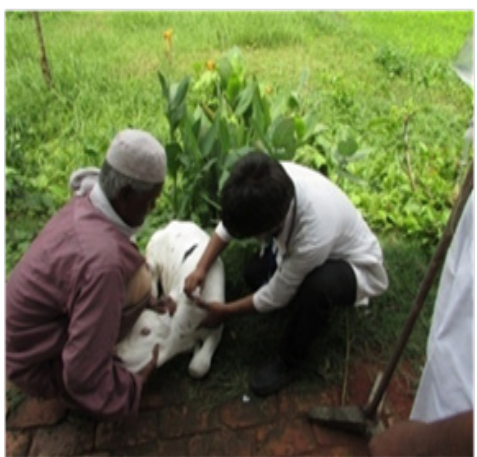

Figure ID Drug administration of calfin calf.

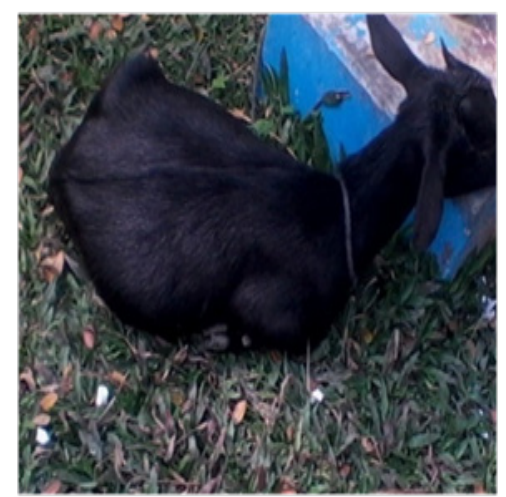

Figure IB Lethargic goat of goat.

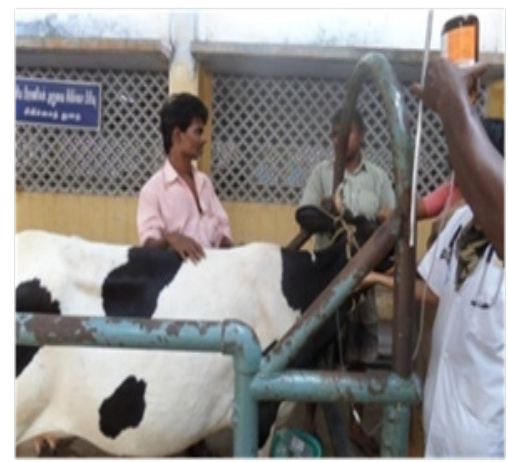

Figure IE Calcium therapy.

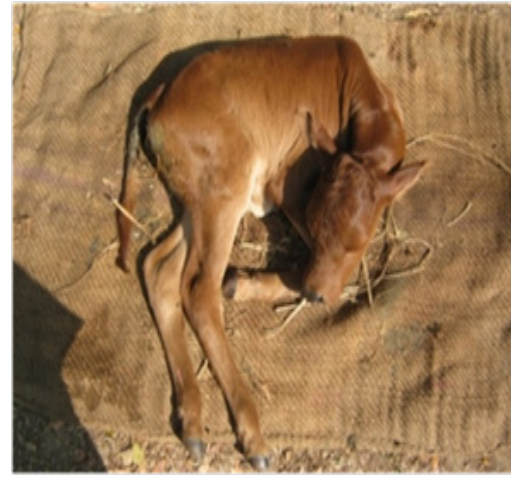

Figure IC Lateral recumbency.

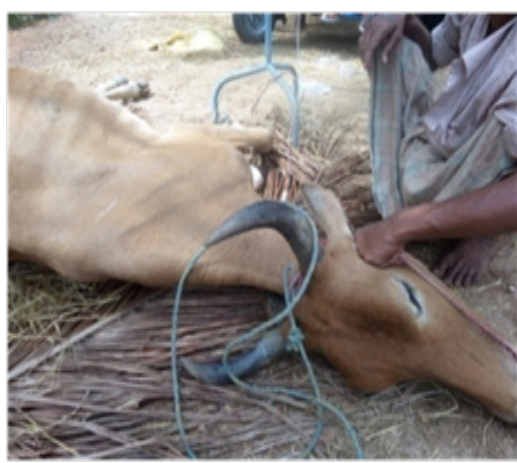

Figure IF Lateral recumbency in cattle.

Figure I Typical clinical signs of hypocalcaemia observed for cattle and goat.

Table 5 Treatment prescribed against hypocalcaemia in cattle and goat and their response

\begin{tabular}{lllll}
\hline Species & Drug and route & Dose & Recovered no. & Died no. \\
\hline & Cal D Mag and IV/SC & $2 g / 100 \mathrm{~kg}$ body weight & & 7 \\
Cattle & $5 \%$ DNS and IV/SC & Based on level of dehydration & 11 & 3 \\
& Vitamin ADE and IM & $15-20 \mathrm{ml}$ & 12 & 3 \\
\hline
\end{tabular}

IV, intravenous; IM, intramuscular; SC, subcutaneous; BW, body weight

Citation: Quader MN, Islam KMF, Jalal S, et al. Investigation of clinical hypocalcaemia in cattle and goats at the selected veterinary hospitals in Bangladesh and India.J Dairy Vet Anim Res. 2017;5(I):33-36. DOI: 10.15406/jdvar.2017.05.00I30 


\section{Discussion}

When serum calcium level falls below $10 \mathrm{mg} / \mathrm{dl}$ or less then the condition is called hypocalcaemia. It frequently occurs in cattle, goat, sheep, buffalo etc. Hypocalcaemia abruptly reduces milk production. Cattle were more commonly affected by hypocalcaemia than goats in this study which is supported by a previous study. ${ }^{12}$ This could be because cattle is large animal and produce more milk and therefore needed for more $\mathrm{Ca}$. Cross breed had more hypocalcemic case in this investigation which is similar to the finding of ${ }^{9}$ and it may be due to more milk production occurred in cross breed than local and thus more $\mathrm{Ca}$ losses through milk and hence hypocalcaemia occurs. Higher number of cases in the female and older cattle in the present study corresponds to the study performed by. ${ }^{13}$

Jamnapari appeared more hypocalcaemia than local indigenous goats in this study. It may be due to larger body size than local. However, a study conducted by Littledike $\mathrm{ET}^{14}$ reported the greater hypocalcaemia cases in local indigenous goat. In present study, the unable to move was predominant clinical sign in hypocalcemic cattle which is well supported by earlier studies. ${ }^{15-17}$ In goat recumbency was commonly encountered clinical signs in present study, which is supported by Ramberg $\mathrm{A}^{18}$ Hypocalcemic cases of cattle and goat treated with the combination of Caborogluconate, Vitamin (ADE) and DNS were successful in recovery of cases in this study which suggests treatment given was satisfactory. This result conforms to other studies. ${ }^{10,11}$

\section{Limitations}

The present study includes small area, short time period and less number of cases. Diagnosis was broadly based on clinical signs. Inclusion of retrospective hypocalcaemia was also a limitation as information of retrospective cases was not as accurate as prospective cases.

\section{Conclusion}

Hypocalcemiccases were significantly higher in the cattle than in goats. Cross breed (cattle), Jamnapari, female and older animals were commonly affected by hypocalcaemia. Common clinical signs were unable to move and recumbency. Calcium preparation along with vitamin $\mathrm{ADE}$ and DNS was successful in recovery of most of the cases. ${ }^{19-22}$

\section{Acknowledgements}

None.

\section{Conflict of interest}

Author declares that there is no conflict of interest.

\section{References}

1. Emanuelson U, Oltenacu PA. Incidences and effects of diseases on the performance of Swedish dairy herds stratified by production. $J$ Vet Sci. 1998;81(9):2376-2382.

2. Constable G. Effect of estrogen on brain activation patterns in animal. JAMA. 1999;281(3):1197-1202.
3. Goff JP. The monitoring, prevention and treatment of milk fever and subclinical hypocalcemia in dairy cows. Vet J. 2008;176(1):50-57.

4. Tsioulpas A, Grandison AS, Lewis MJ. Changes in physical properties of bovine milk from the colostrum period to early lactation. J Dair Sci. 2007;90(11):5012-5017.

5. Van De BraakAE, Van T KloosterAT, Malestein A. Influence of a deficient supply of magnesium during the dry period on the rate of calcium mobilisation by dairy cows at parturition. Res Vet Sci. 1987;42(1):101-108.

6. Rahman MM, Haque MN. Productive and reproductive performances of native cows under farm conditions. In Biol Sci. 2001;1(11):1085-1087.

7. Roche JR, Berry DP. Periparturient climatic, animal, and management factors influencing the incidence of metabolic disease in grazing systems. J Dair Sci. 2006;89(7):2775-2783.

8. Meléndez E. Titanium complexes in cancer treatment. Crit Rev Oncol. 2002;42(3):309-315

9. Inoue A, Suzuki T, Fukuhara T, et al. Prospective phase II study of gefitinib for chemotherapy-naive patients with advanced non-small-cell lung cancer with epidermal growth factor receptor gene mutations. J Clin Oncol. 2006;24(21):3340-3346.

10. Pehrson JR, Fuji RN. Evolutionary conservation of histone macroH2A subtypes and domains. Nuc Aci Res. 1998;26(12):2837-2842.

11. Goff JP, Horst RL. Oral administration of calcium salts for treatment of hypocalcemia in cattle. J Dair Sci. 1993;76(1):101-108.

12. Lean DR, Celo V, Scott SL. Management and treatment of metabolic Disease. J Vet Res. 2006;368:126-137.

13. Quarles LD, Sherrard DJ, Adler S, et al. The calcimimetic AMG 073 as a potential treatment for secondary hyperparathyroidism of end-stage renal disease. J Am Soc Nephrol. 2003;14(3):575-583.

14. Littledike ET, Goff J. Interactions of calcium, phosphorus, magnesium and vitamin $\mathrm{D}$ that influence their status in domestic meat animals. $J$ Anim Sci. 1987;65(6):1727-1743.

15. Shank RP, Aprison MH. Present status and significance of the glutamine cycle in neural tissues. Life Sci. 1981;28(8):837-842.

16. Perry EK, Curtis M, Dick DJ, et al. Cholinergic correlates of cognitive impairment in Parkinson's disease: comparisons with Alzheimer's disease. J Neurol Neurosurg Psychiatry. 1985;48(5):413-421.

17. Stevenson MA, Lean IJ. Descriptive epidemiological study on culling and deaths in eight dairy herds. Aus Vet J. 1998;76(7):482-488.

18. Ramberg A. Measurement of Nuclear Transparencies from Exclusive $\rho^{0}$ Meson Production in Muon-Nucleu. Phys Rev lett. 1995;74(9):1525.

19. Rude RK. Magnesium deficiency: a cause of heterogenous disease in humans. J Bon Min Res. 1998;13(4):749-758.

20. Schwingenheuer B, Briere RA, Barker AR, et al. CPT tests in the neutral kaonsystem. Phy Rev let. 1995;74(22):4376.

21. Fork RL, Greene BI, Shank CV. Generation of optical pulses shorter than $0.1 \mathrm{p}$ sec by colliding pulse mode locking. Ap Phys Lett. 1981;38(1):671-672.

22. Costanzi C, Pehrson JR. Histone macroH2A1 is concentrated in the inactive X chromosome of female mammals. Nature. 1998;393:599-601. 